DOI: $10.5604 / 01.3001 .0012 .8038$

\title{
INFORMATION SYSTEM FOR ASSESSING THE PROFESSIONAL ACTIVITIES COMPLEXITY - THEORETICAL AND PRACTICAL ASPECTS OF IMPLEMENTATION
}

\author{
Oleg Zaritskyi \\ National Aviation University, Information Technologies Security Department, Educational and Scientific Institute of Information and Diagnostic Systems
}

Abstract. The article deals with theoretical and practical issues of the implementation of professional activity analytical evaluation information technologies. The focus is on new methods for presenting and processing data in the activity description and evaluation tasks.

Keywords: information system, profession activity estimation, job analysis, graphs theory, fuzzy set

\section{SYSTEM INFORMACYJNY DO OCENY ZLOŻONOŚCI DZIALALNOŚCI ZAWODOWEJ - TEORETYCZNE I PRAKTYCZNE ASPEKTY WDROŻENIA}

\begin{abstract}
Streszczenie. Artykut dotyczy teoretycznych i praktycznych zagadnień wdrażania technologii informatycznych do analitycznej oceny aktywności zawodowej. Nacisk kładziony jest na nowe metody prezentacji i przetwarzania danych w opisie i ocenie zadań.
\end{abstract}

Slowa kluczowe: system informacyjny, szacowanie działalności zawodowej, analiza pracy, teoria grafów, zbiór rozmytych

\section{Introduction}

Nowadays, society is on the verge of the fourth industrial revolution. The development of engineering science and information technology (IT) in the field of genetics, artificial intelligence, robotics, nanotechnology, 3D printing technologies and complementary biotechnologies accelerates the processes of innovation in almost all industries [16, 17]. Changes in business models and their almost complete rebuilding will significantly affect the professional activity market in the next 5-10 years. Most of the characteristic indicators or markers of industrial transformation that affect the development of industry will have a significant impact on professional activity. They will induce the intensive emergence of new types of professional activity, the alternation or disappearance of existing ones and, consequently, will change the concepts of enterprise resource management, including human one.

Major changes will take place in the field of labour productivity, which is determined by a number of factors, including wage flexibility, which will increasingly be described by factor-based models and wage systems, which are formed according to the estimates of work complexity.

It should be noted that currently there are no generally accepted theoretical and methodological foundations as regards the formal description, modelling and classification of professional activities, and analytical assessment of the work complexity within such activities, which makes it almost impossible systematic collection of information and processing with the help of IT.

The problems of theoretical and methodological development of professional activity analytical evaluation are devoted by the works of scientists [3, 6-11,13].

There are a certain number of structural models in the format of a simplified graphical description of the professional activity, which gives an idea of common factors set that describe the main functional areas in its content. The peculiarity of the considered models is their orientation to the simulation of certain types of professional activity, which significantly limits the possibility of their application for a wide range of occupations, that is, one of the general requirements for models - universality is not fulfilled.

One way to solve the issue of universality is to define the minimum and the required number of factors of the model and their characteristics, which provide conditions of maintaining the professional activity content i.e. adequacy of the model. The second one is to increase the number of characteristics described by various scales, including linguistic variables, given by fuzzy sets, which leads to a complication of the model.
Obviously, there is an optimal solution to simultaneously ensure the adequacy and universality of the model in terms of minimizing its structural elements number.

The author examines the theoretical and methodological foundations of professional activity analytical evaluation in terms of the system of principles and methods of organization, construction theory and practice of analytical evaluation, as well as the doctrine of the system itself. The methodology involves a combination of research methods and strategies and also certain hypotheses and ideas that need to be clarified and confirmed by relevant research:

1. It is assumed, that in any profession it is possible to identify and assess a set of common factors that describe the main functional areas in its content.

2. In fact, it is possible to allocate the minimum and the sufficient number of structural elements to ensure the adequacy of the model.

3. It is supposed that the presentation of professional activity in the form of a graph will allow to investigate it as a system of interconnected operations and to calculate their weight characteristics.

4. It is assumed that the use of methods of fuzzy set theory to describe the weakly structured elements of the model (factors, characteristics), will allow to ensure its universality.

\section{Conceptual model of professional activity}

It should be noted that the existing conceptual models do not carry a meaningful load, but are used only for the formalization of the subject and object of research. The meaningful analytical evaluation of professional activity involves the presentation and processing of quantitative data using the theory of information and methods of mathematical apparatus and modelling.

Mathematical modelling involves the creation of an ideal structure, the so-called conceptual (content) model, but on a deeper level. Its development allows one to formalize with certain assumptions the main structural elements and relationships between them, with a subsequent description by means of mathematical expressions in the form of a formal or mathematical model. Content models are constructed using ready-made designs, developed in the form of hypotheses.

Professional activity belongs to the field of knowledge in which all theories are in a constant process of development and refinement, which greatly complicates the development of conceptual models that are classified depending on the depth of description and understanding of the formalized phenomenon and create a certain hierarchy. Based on fundamental research [5], which formalizes mathematical models for the analysis 
of phenomena in the humanities, a meaningful model of professional activity can be built within hypotheses and phenomenological models that differ in the level of description and detail of structural elements.

The conceptual model is used to formalize the boundaries of the research object. It should also be further detailed concerning the transition directly to the subject of research within the framework of the corresponding structural and information models, detailed to a level of sufficiency and necessity for the description and analysis of professional activity - the level of entities and attributes.

Analytical evaluation of professional activity involves the allocation of the structural elements (entities) of the model's upper-level characteristics (Fig. 1) [21, 22], which, in turn, combine the characteristics of individual operations on certain features: educational-qualification level, methods and means of operations etc.

The proposed method of allocating structural elements of professional activity and combining them with a clearly defined feature in groups allows us to obtain a structural model of professional activity at a more detailed level in which the main emphasis is on the characteristics of entities and the connection between them as elements of a complex system (Fig. 1).

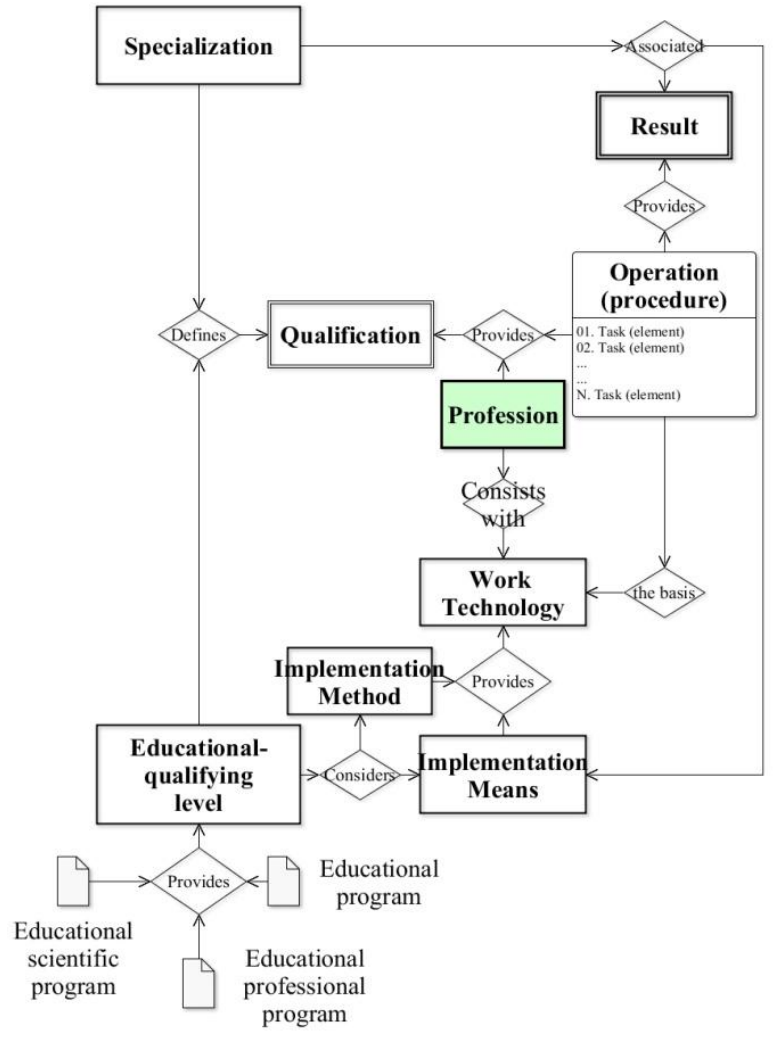

Fig. 1. Structural model of professional activity

Structural model is a system of domain elements - factors of the model (structural elements of the first level), links between them and the mechanism of functioning, which can be presented as a knowledge base, built on the rules, or mathematical expressions.

Thus, professional activities consist of the number of successive or parallel operations and procedures defined in the process of division of labor, which in general form the technology of work or management.

The technology of works (including management) is a rational sequence of operations and procedures (information, logicalthinking, settlement, organizational, etc.) that are performed by the executors using specific means and methods of production in order to influence the object of management.
The basis of the repetitive work technology is the operation (Fig. 1). It represents a homogeneous, logical, indivisible part of the process of work execution or management. The notions of "operation" and "procedure" are key ones in the technology of professional activity study. Along with this, the term "operation" has a broader meaning and covers any useful action of a person - production, technological, managerial, etc.

Operation is any action, measure (or system of events) that is united by a single plan and aimed at achieving an appropriate purpose. The complex of actions carried out within the framework of one operation may consist of several elements (tasks), therefore the operation can be considered as a set of elements (tasks) of labor processes performed by employees. The basis for the construction of operations should be, above all, the target completion of the performance.

Thus, the operation (task) is the basic element of professional activity, which was formalized in the form of a structural model for further information modeling within the framework of constructing a methodology for analytical evaluation of professional activity $[14,15,20,21]$.

\section{A new approach in work presenting}

The conceptual structure of the subject area was represented as a plurality of structural elements, that are individually described by the basic characteristics [21].

The analytical evaluation of professional activity involved the calculation of each operation weight within the profession (job) and rankings of occupations. Such an assessment is possible only with the use of a mathematical apparatus for describing information models developed by the author in order to obtain quantitative characteristics of work [19].

The main purpose of the mathematical modelling of professional activity is the study of the model entities (structural elements) in their description by means of mathematical relations. In general, the characteristics of the professional activity model structural elements can be represented by matrix $A$ :

$$
A\left(a_{i j}\right)_{\substack{i=1, n \\
j=1, k}}=\left(\begin{array}{ccc}
a_{11} & \ldots & a_{1 k} \\
\ldots & \ldots & \ldots \\
a_{n 1} & \ldots & a_{n k}
\end{array}\right),
$$

where $\left(a_{i j}\right)$ is the evaluation of the entity attribute, $n$ is the number of operations (tasks) within the professional activity, $k$ is the number of attributes describing the nature of the model.

Each structural element of the professional activity model is calculated as the average of the estimates for each operation with the corresponding weighting factors $\omega_{i}$ :

$$
\begin{gathered}
s_{e_{j}}=\frac{1}{n} \sum_{i=1}^{n} \omega_{i} \tilde{a}_{i j}, \\
\tilde{a}_{i j}=\frac{a_{i j}}{a_{i j_{\max }}},
\end{gathered}
$$

where $a_{i j_{\max }}$ is maximum value of the $i$-th attribute.

Based on the characteristics of the parameters, the model of professional activity is deterministic, discrete and stationary, since it describes the steady state of the system only for discrete values of its variables (attributes). For the first time, the calculation of weights of each operation was introduced into the model, which significantly reduced the impact of operations that occupy a small share in the total working time fund, on the overall professional activity assessment.

Since the weight coefficients in the mathematical model do not take into account the interconnections between the operations, the author proposes to consider the activity in terms of the theory of graphs, which will enable the calculation of coefficients that characterize each operation on certain features. 


\subsection{Professional activity graph}

Professional activity is described by the non-oriented graph, which is given by matrices of adjacency and incidence, the analysis of which allows revealing the main characteristics of the operation: importance factors, ranking (Fig. 2, second and third digits) and clustering, which significantly affect the activity in general $[4,12]$.

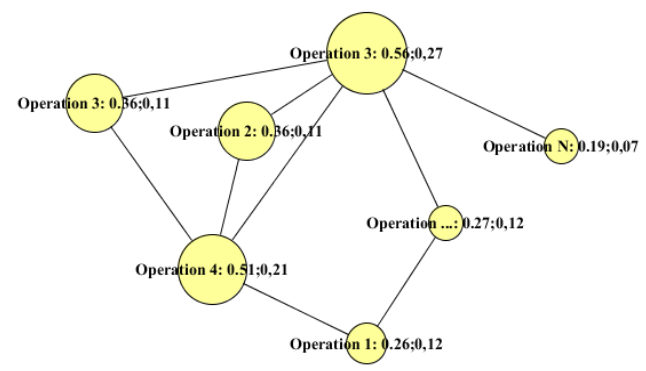

Fig. 2. Professional activity graph

The clustering factor reflects how much the operations tend to make a connection if they are connected through a third operation:

$$
C_{i}=\frac{2\left|\left\{e_{j k}: v_{j}, v_{k} \in N_{i}, e_{j k} \in E\right\}\right|}{k_{i}\left(k_{i}-1\right)},
$$

where $k_{i}$ is the number of operations on the set of adjacent operations: $N_{i}=\left\{v_{j}: e_{i j} \in E \vee e_{j i} \in E\right\} . \quad V$ is the set of operations, and $\mathrm{E}$ is the set of connections between them.

The weight of the operation on the basis of connections - the calculation of the weight of the operation on the basis of its connections within the activity - a recursive characteristic, which determines the impact of the operation on the activity as a whole:

$$
x_{i}=\frac{1}{\lambda} \sum_{j \in G} a_{i j} x_{j},
$$

The importance of the operation in terms of the switching function (located on the shortest distance between the two other paths):

$$
C_{D}(v)=\sum_{i \neq v \neq j \in V} \frac{\sigma_{i j}(v)}{\sigma_{i j}},
$$

where $\sigma_{i j}$ is total number of the shortest paths between operations, $\sigma_{i j}(v)$ is the number of shortest paths that pass through the operation $v$.

The importance of the operation in terms of the minimum average distance to other operations:

$$
C_{L}\left(v_{i}\right)=\sum_{j} \frac{1}{d\left(v_{j}, v_{i}\right)},
$$

where $d\left(v_{j}, v_{i}\right)$ is distance between operations $v_{j}, v_{i}$.

The calculated coefficients (3-6) are taken into account when weighting factors $\omega_{i}$ are calculated.

\subsection{Representation of weakly structured characteristics of the professional activity model}

Subject area of research - professional activity, expressed by models, described by entities in terms of their attributes and relationships between them. Within the scope of the research, a field of knowledge was defined - a model of knowledge about the subject field [18]:

$$
N_{p}=\left(S_{p_{d}} ; R_{a_{p}} ; A^{r} \rightarrow A^{s} ; R_{b_{p}}\right),
$$

where $S_{p_{d}}$ is description of the class of situations; $R_{a_{p}}$ is the condition under which the products are activated; $A^{r} \rightarrow A^{s}$ is the core of products (7); $R_{b_{p}}$ is condition (action) to be performed after the kernel is implemented:

$$
P_{t}=\bigwedge_{r=1, r} A^{r} \rightarrow \bigwedge_{s=1, s} A^{s}
$$

where $P_{t}$ is the designation of products; $t$ is the number of products in the production model; $A^{r}$ is the variable predicate (fact) from $r$ variables, which is called parcel; $A^{s}$ is a variable terminal predicate from $s$ variables, which is called the conclusion.

Developing ideas presented by the fourth hypothesis, the author proposes to describe the weakly structured elements of the professional activity model by linguistic variables using the theory of fuzzy sets. Templates of presentation products in the expert system taking into account (7-8) and the syntax of the productive programming language CLIPS [18] are presented as designs:

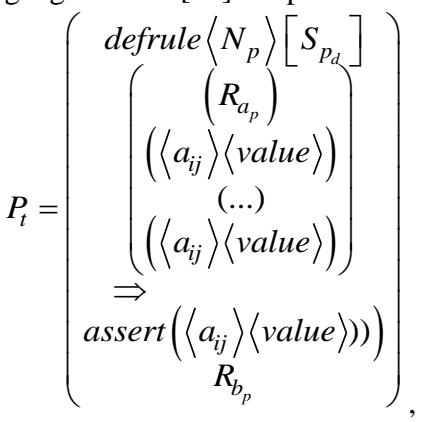

The method of analysis of weakly structured data is directed at solving the problem of description, calculations and numerical representation of the operation characteristics, described by weakly structured data. The algorithmic part is given by the mathematical apparatus of the theory of fuzzy sets, the logic of the machine of logical output and the rules of the knowledge base in the form of a production model.

As a result of the logical output machine operation, linguistic variables were obtained (9), the transition to their numerical representation was realized due to the usage of standard methods in the theory of fuzzy sets [2].

\section{Information system of professional activity evaluation}

Analytical evaluation as information technology is considered from the point of view of the combination of data processing technology and expert systems, which represents a set of methods, production processes, software and hardware integrated with the purpose of collecting, processing, storing, disseminating, demonstrating and using structured information and analytical assessment with the purpose to make managerial decisions.

Taking into account the results of investigations of modern information systems functional structures [1], methods and tools for evaluating the work's complexity, theoretical approaches to formalize the tasks of professional activity evaluation with the help of expert systems, there was developed the structural scheme of intellectual IT of analytical assessment based on knowledge. The diagram of the calculation part of the information system is presented in (Fig. 3), it includes three main blocks: a block of graphical representation of the activity model, a block of representing operations in the form of linguistic variables, and directly a block of calculations.

The technology of professional activity analytical evaluation involves the formalization of specific tasks of assessment (classification) and the use of developed tools for the implementation of the evaluation system itself.

Experts (operators) enter data on aspects (factors) of work at the level of their attributes (Fig. 4). 


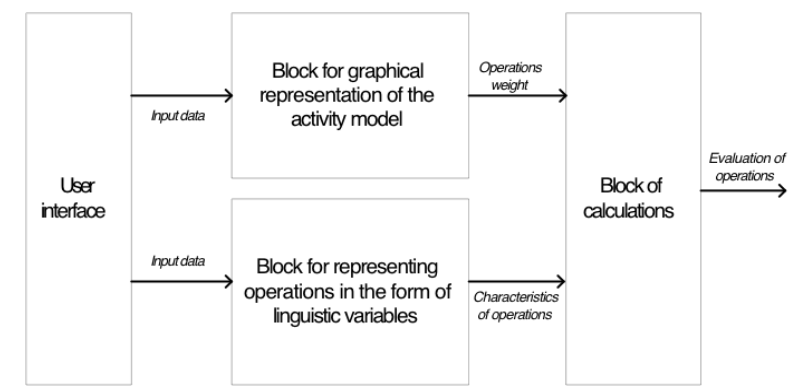

Fig. 3. Algorithmic part of the information system

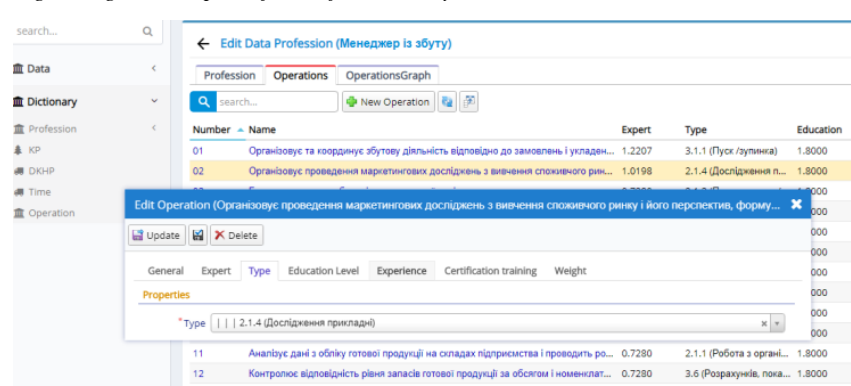

Fig. 4. Analysis and description of the model factors

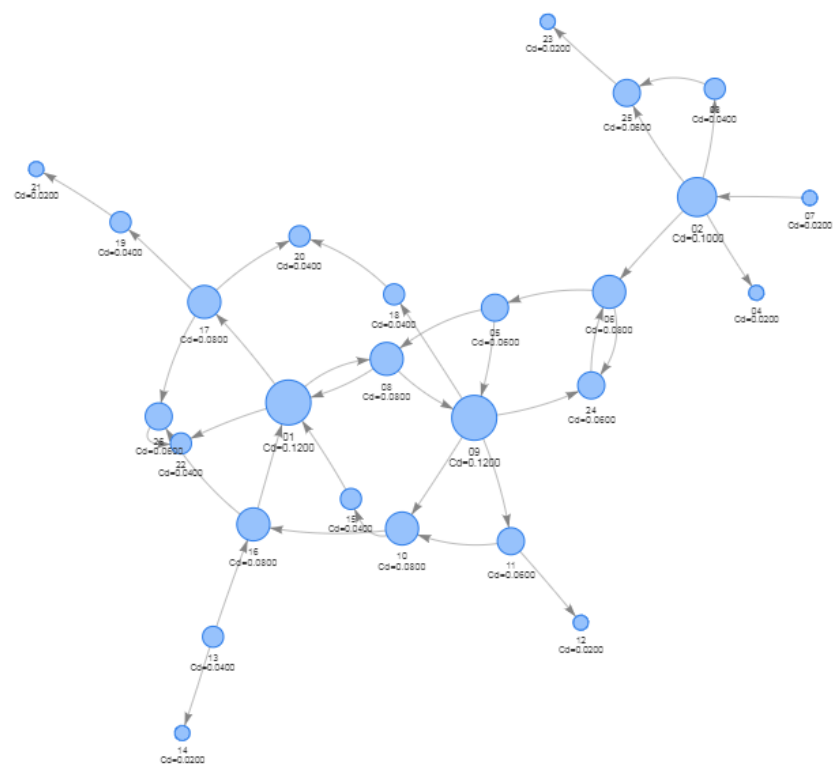

Fig. 5. Professional activity graph

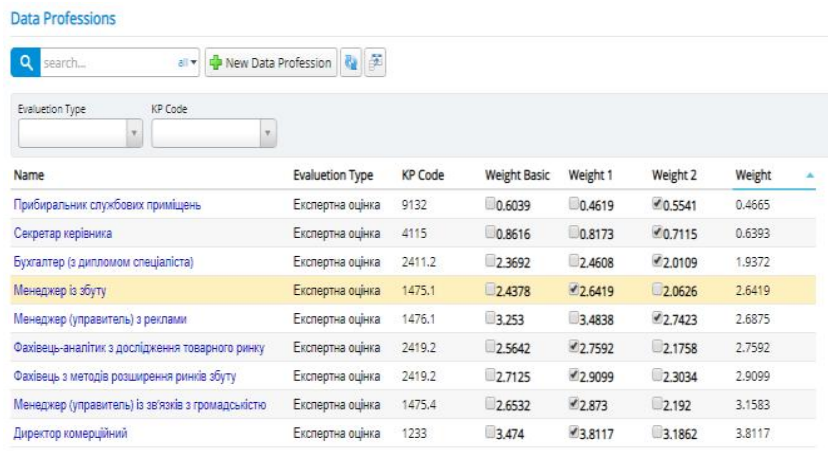

Fig. 6. Evaluation of profession

The block of the graphical representation of the activity represents the model in the form of interrelated operations and calculates the operations weight coefficients (3-6) (Fig. 5).

The algorithmic part of the method ensures the automatic formation of adjacency and incidence matrices on the basis of the introduced operations and the connections between them.
The calculation unit implements the developed algorithms $(1,2,7-9)$ for quantitative estimation of operations (Fig. 6).

The peculiarity of the technology implementation is the need for the integration of data obtained using the developed algorithmic and production programming languages algorithms, i.e., different principles of data processing.

\section{References}

[1] CLIPS Architecture Manual. Version 5.1. Johnson Space Center, Washington 1992

[2] CLIPS Reference Manual. Volume I. Basic programming guide. Version 6.22. Johnson Space Center, Washington 2004

[3] Fine S. A., Cronshaw S. F.: Functional job analysis: A foundation for human resources management. Lawrence Erlbaum Associates Publishers, Mahwah 1999.

[4] Girvan M., Newman M. E. J.: Community structure in social and biological networks. Proceedings of the National Academy of Sciences 99(12), 2002, 7821-7826.

[5] Gorban A., Kazantis N.: Model reduction and Coarse-Graining Approaches for multiscale phenomena. Springer-Verlag Heidelberg, Berlin 2007.

[6] Harvey R. J.: Research Monograph: Development of the Common-Metric Questionnaire (CMQ). Personnel Systems and Technologies Corporation, 1999.

[7] Harvey R. J : The common-metric questionnaire (CMQ): A job analysis system. First edition. The Psychological Corporation, San Antonio 1991.

[8] McCormick E. J., Cunningham J. W., Gordon G. G.: Job dimensions based on factorial analyses of worker-oriented job variables. Personnel Psychology, 1967 [doi: 10.1111/j.1744-6570.1967.tb02442.x].

[9] McCormick E. J., Jeanneret P. R., Mecham R. C.: The development and background of the position analysis questionnaire (PAQ). Occupational Research Center Purdue University Lafayette, Indiana 1969.

[10] McCormick, E. J., Jeanneret, P. R., Mecham, R. C.: A study of job characteristics and job dimensions as based on the Position Analysis Questionnaire (PAQ). Journal of Applied Psychology 56(4), 1972, 347-368.

[11] Miller B. Z.: Organization theory: study. INFRA-M, Moscow 2005

[12] Pons P., Latapy M.: Computing communities in large networks using random walks. Computer and Information Sciences-ISCIS 2005, 284-293.

[13] Prigozhin A. I.: Methods of organization development. MCFER, Moscow 2003.

[14] Simon H. A.: A Behavioral Model of Rational Choice. Quarterly Journal of Economics 69, 1955, 99-118.

[15] Simon H. A.: Rational Decision-Making in Business Organizations. A Nobel Memorial Lecture - Economic Sciences, 1978, 343 - 371.

[16] The Future of Jobs Employment. Skills and Workforce Strategy for the Fourth Industrial Revolution - Global Challenge Insight Report. World Economic Forum, Cologny 2016.

[17] The Global Competitiveness Report 2016-2017 - Insight Report. World Economic Forum, Cologny 2017.

[18] Zaritskiy O., Pavlenko P., Tolbatov A.: Data representing and processing in expert information system of professional activity analysis. Proceedings of the 13th International Conference on Modern Problems of Radio Engineering, Telecommunications and Computer Science, Lviv 2016, 718-720.

[19] Zaritsky O., Sudik V.: Development of a mathematical model of professional activity. Eastern European Journal of Advanced Technologies "Technological Center" 1/ 4 (79), 2016, 10-18.

20] Zaritsky O.: Application of the basics of communication theory for the development of information systems for the modeling of professional activities. Bulletin of the Chernihiv State Technological University - Series "Technical Sciences" 1 (1), 2015, 94-98.

[21] Zaritsky O.: Functional modeling of professional activity basic elements within the model "Entity - Communication". Problems of Informatization and Management 2 (50), 2015, 70-75.

[22] Zaritsky O.: Modeling of human professional activity. Materials of abstracts $\mathrm{V}$ international scientific practice conf.: Integrated quality assurance of technological processes and systems, Chernihiv 2015, 202.

\section{D.Sc. Oleg Zaritskyi \\ e-mail: olegzaritskyi@gmail.com}

Associate Professor of the Information Technologies Security Department, Educational and Scientific Institute of Information and Diagnostic Systems, National Aviation University, Kiev, Ukraine. Research interests: information technology, artificial intelligence. Author of more than 50 scientific publications and theses of 20 scientific and technical conferences, 3 certificates of copyright in a work registration.

Scopus Author ID: 57189327322

ORCID ID: 0000-0002-6116-4426

otrzymano/received: 1.10 .2018 przyjęto do druku/accepted: 15.12 .2018

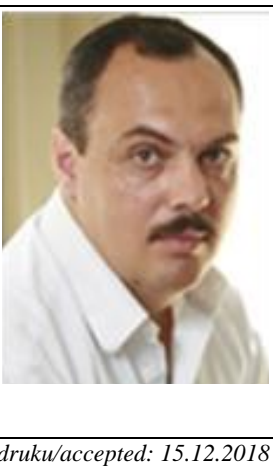

